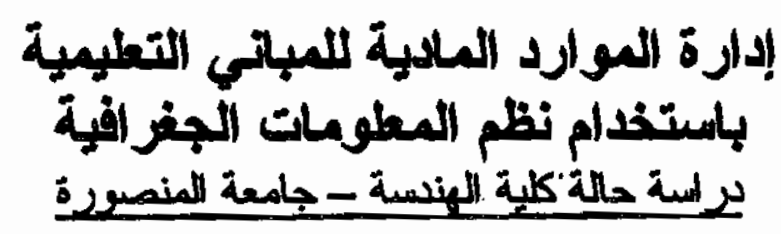

\title{
Material Resources Management for Educational Building Using GIS Case Study: Faculty of Engineering - Mansoura University
}

\author{
Dr. Mohamed M. Shawky Abou-Liela \\ Lecturer of Architecture, Dep. of Architectural Engineering \\ Faculty of Engineering, Mansoura University \\ m_shawky lila@yahoo.com
}

\section{Summary of Research}

This study aims to ascertain the concept of Material Resources Management for Educational Building Using Geographic information system (GIS), as an important means of information management. Enclosing various data and information, university educational buildings requires attentive management to achieve the greatest investment of material resources. The research demonstrates a program designed specifically for managing material resources at the faculty of engineering, Mansoura University in the framework of Continuous Improvement and Qualifying for Accreditation Project (CIQAP) in the faculty over the period of 30 weeks from 2-4-2009 and till 1-10-2011.The research proved its claims through achieving the best management of faculty material resources using GIS. The research also offers different scenarios for crisis management in a way that avoids wasting such resources that are of great value for those buildings.

\section{ملغص البحث}

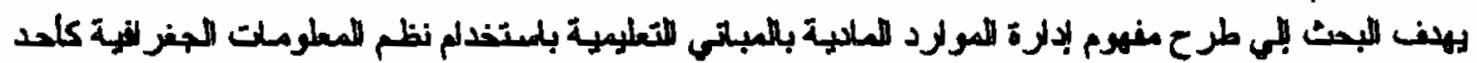

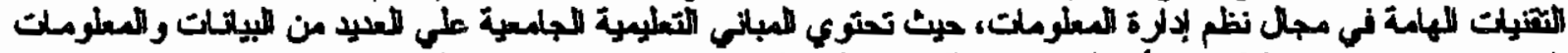

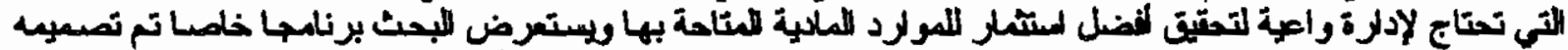

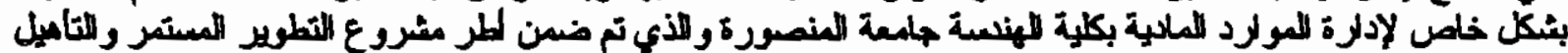

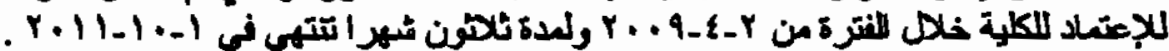

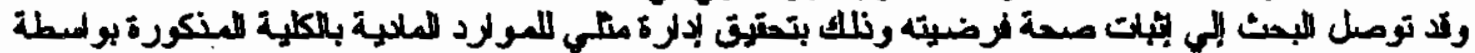

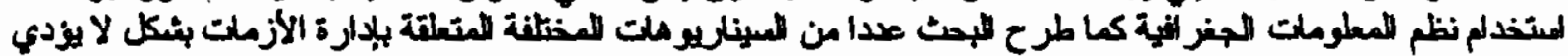

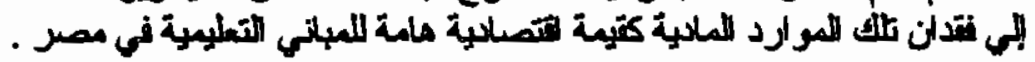
Lulithilist

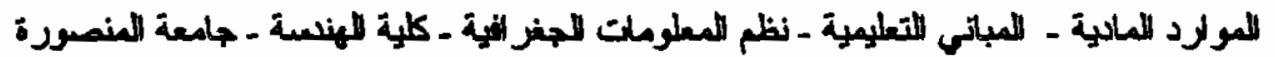


والذي جري من خلمله تصميم وبناء قواعد

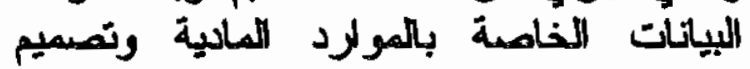

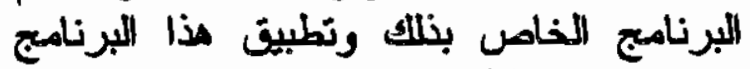

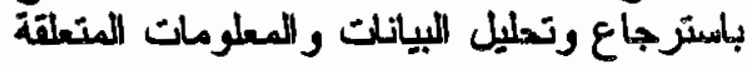
بالموارد المانية باككلية .

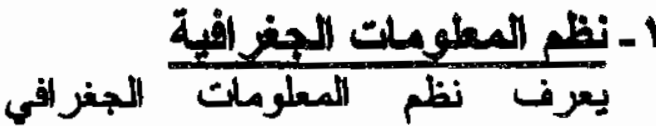

(Geographic Information System : GIS) بأنه نظلم للحاسب : الآلي لجمع وإليخال ومعالجة وتعليل وعرض وإخراج المعلومات لالجغرافية ومالية

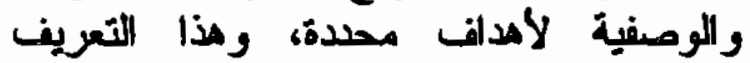

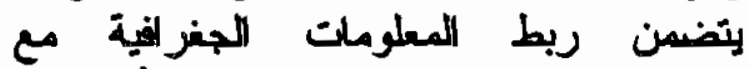

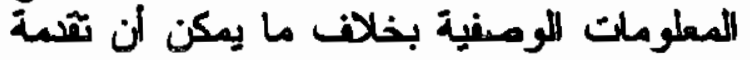

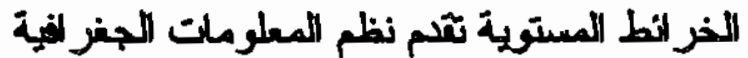

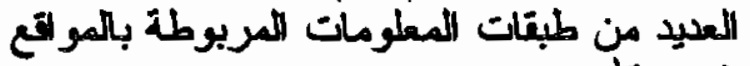
المكانية'

كما بعرف الخزامي نظم المعلومات

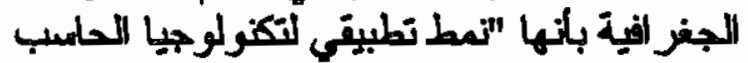

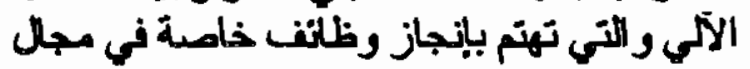

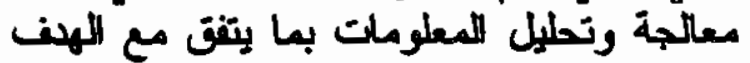

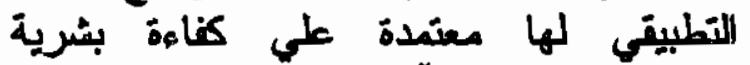
والإكترونية متميزة "r.

ولتد إنتشرت نظم المعلومات الجغرة الغية

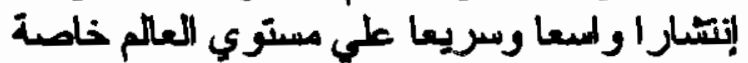

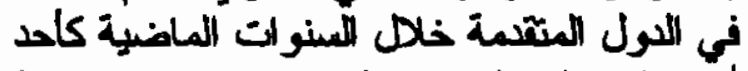

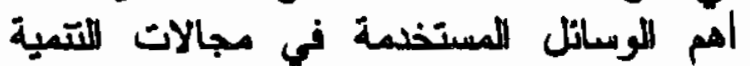

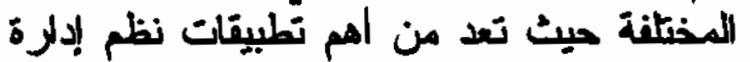

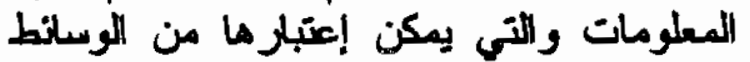

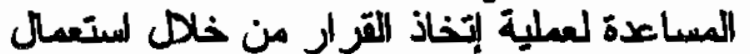

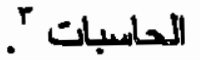

حيث تتميز نظم المعلومات الجنز الفية

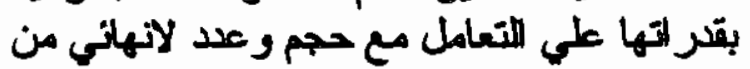

1 Geography Matters $M$ An ESR (1) White Paper (September 2002) URL: htto:/www gis.com/whatisois/geographymatters.pdr

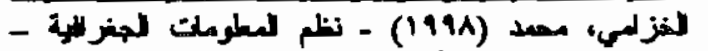

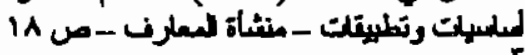

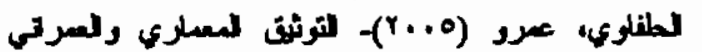

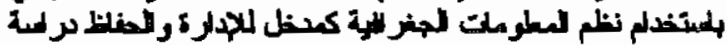

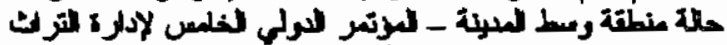

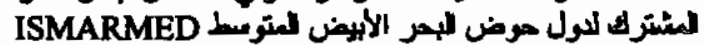

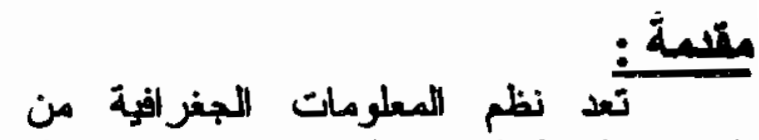

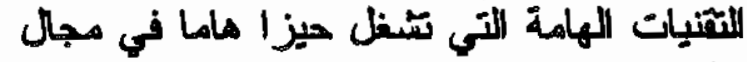

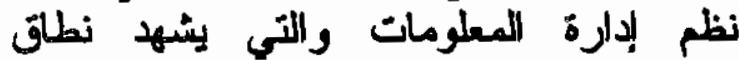

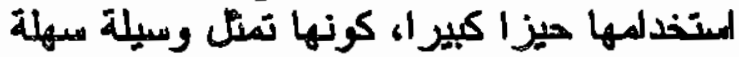

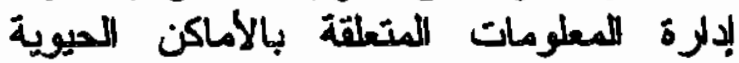

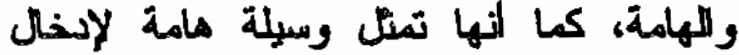

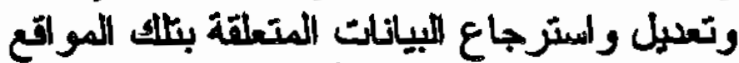

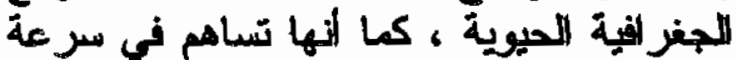

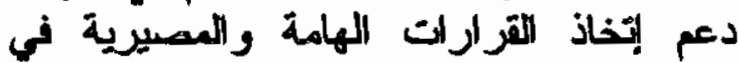

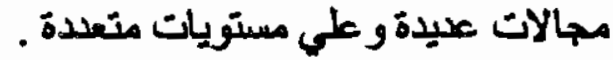

وتمنل المباني التعليمية المجامعية مركزا

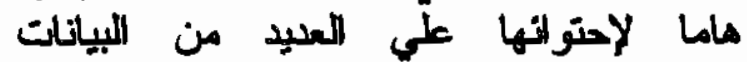

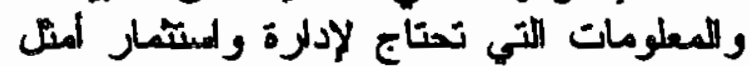

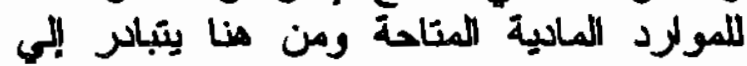

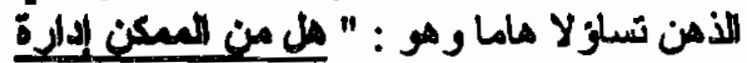

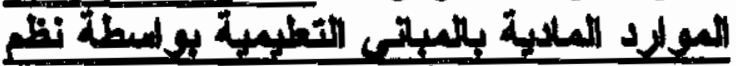

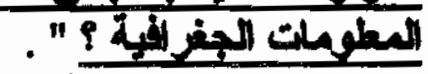

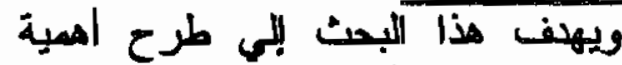

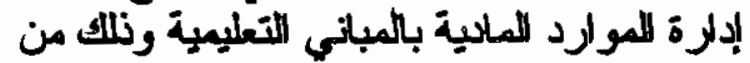

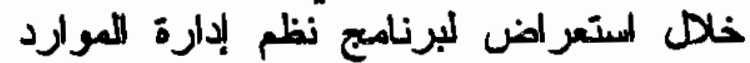

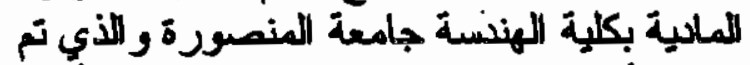
ضمن الطر مشروع اللتطوير المستصر والتأهيل

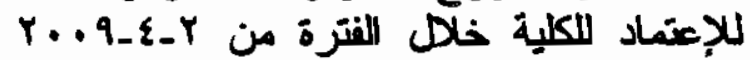

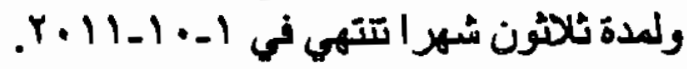

وقد ارتكزت الدراسة علي فرضية

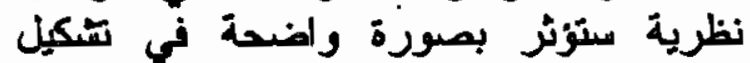

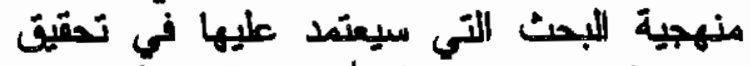

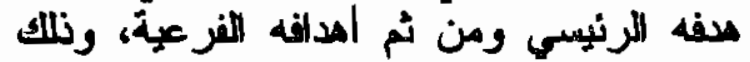

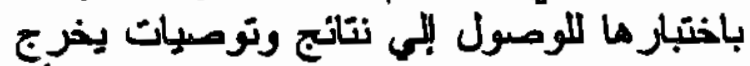

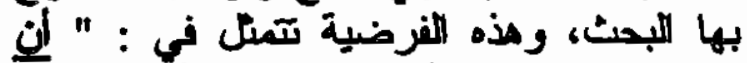

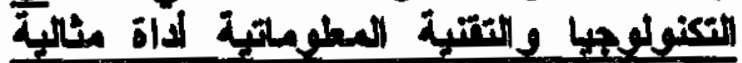

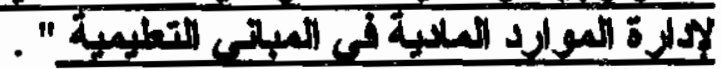

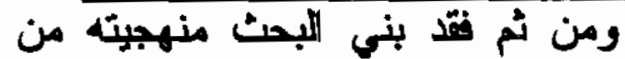

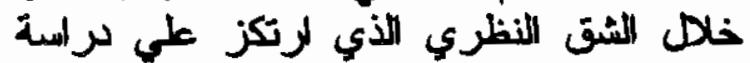

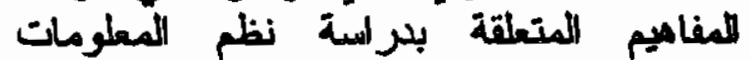

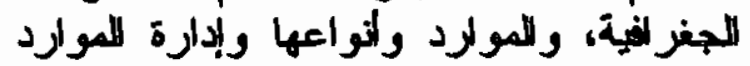

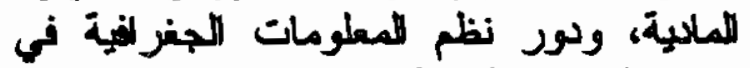

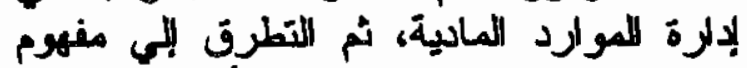

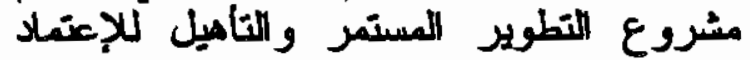




\section{r- إلدالرة الموارد المبلية}

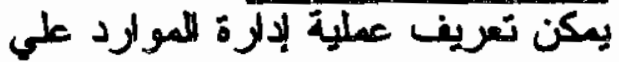

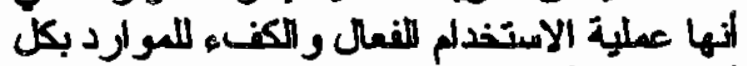

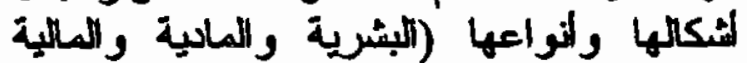

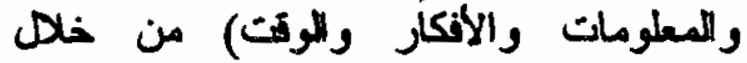

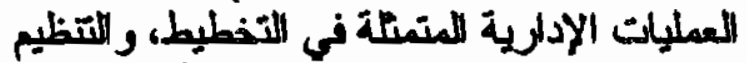

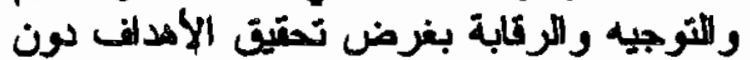

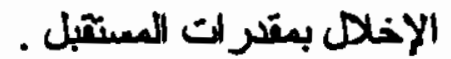

ولم تكن عملية رسم العسيلهيات اللتموية

وربتمار الموارد توخذ في الإعثبار حتى ظهور

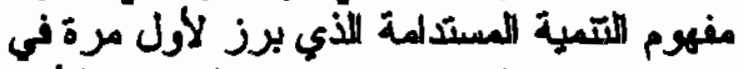
مزتمر لمتكهولم عام

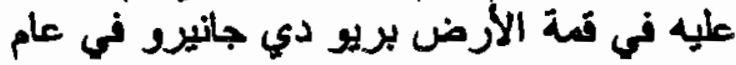

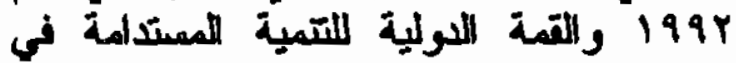

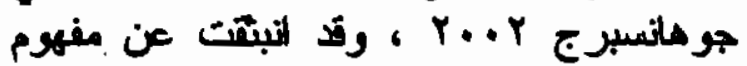

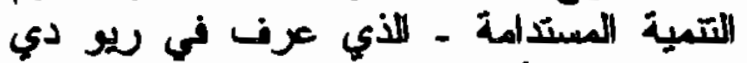

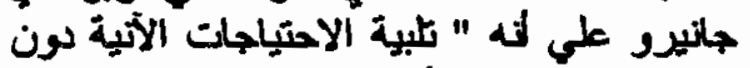

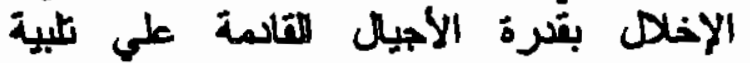

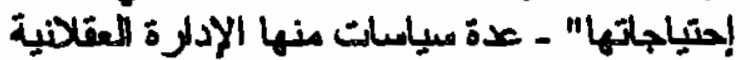

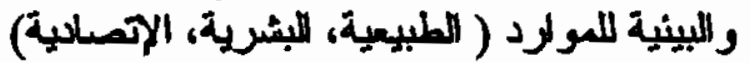

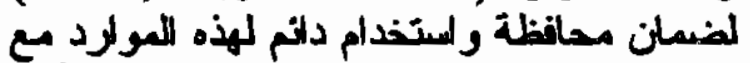

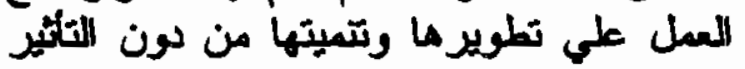
اللسلي على الائئة .

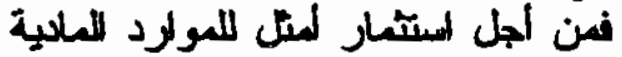

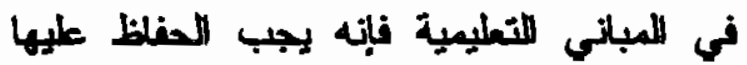

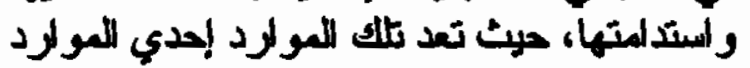

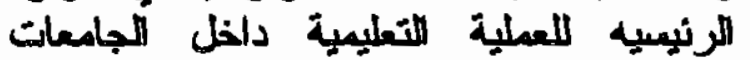

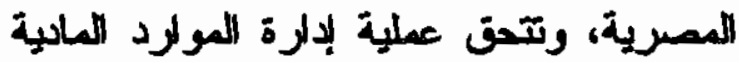

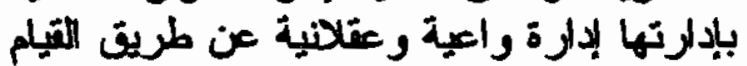
بحصر وتوثين كانة الموارد المادية ولائية المتاحة وبيان حالتها، والثواعها وكمياتها المتاحة والماكن

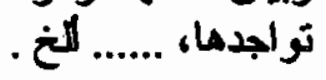

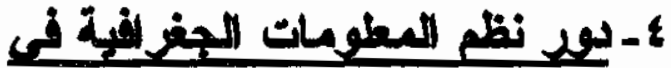

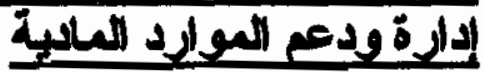

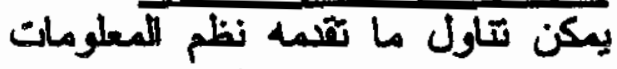

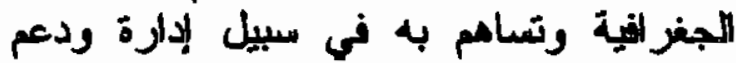

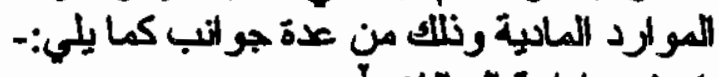 1-6}

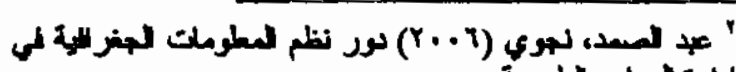

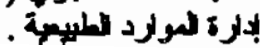

التواع الليانلت مما يسهم في تطوير ورفع كغاعة الادأه، تتقسم هذه البيانات التي قسمين: في : Spatial Data في صورة بيانات خطية : vector data

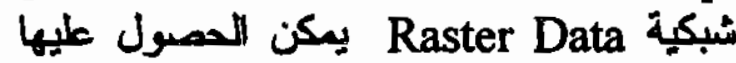
من الخر التط ار مور الاحسر المسناعية.

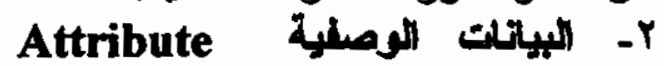
والمائ :Data

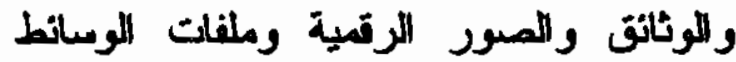
المتعدة

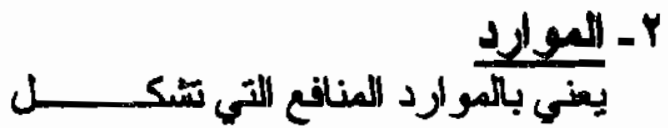

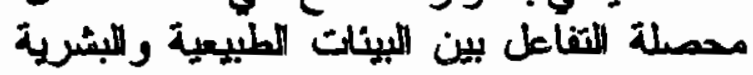

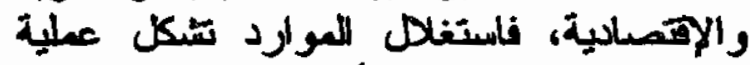

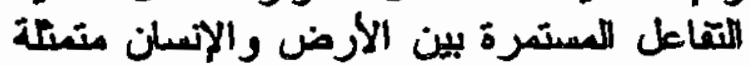

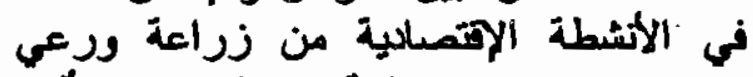

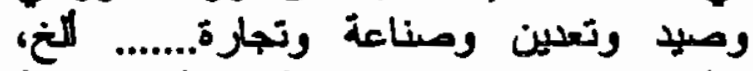

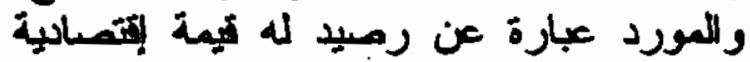

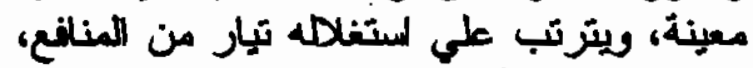

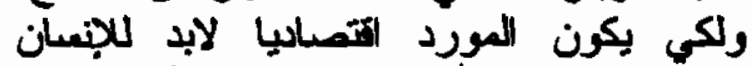

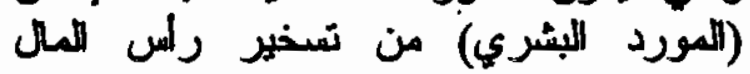

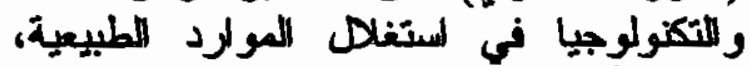

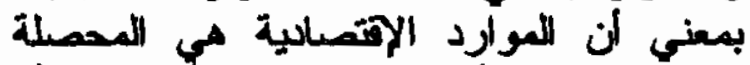

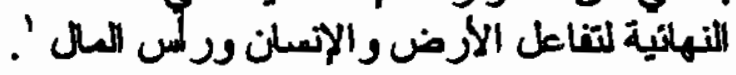

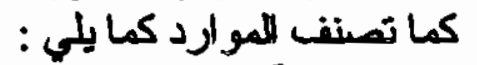

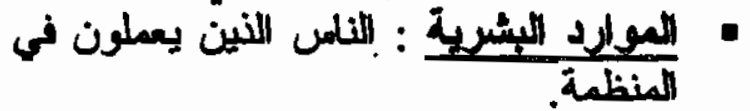

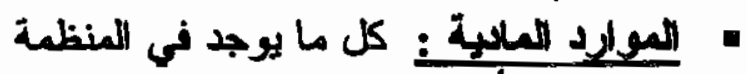

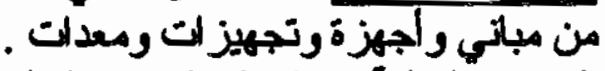

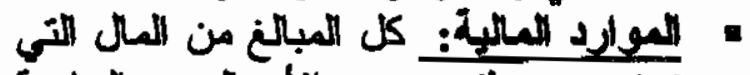

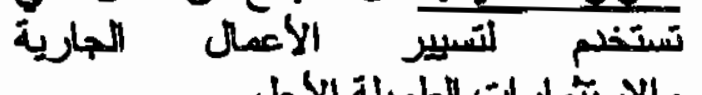

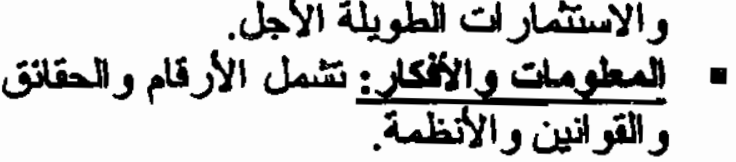

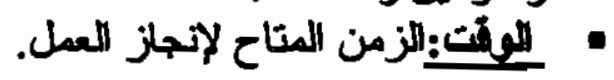

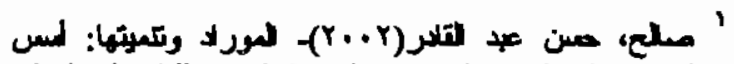

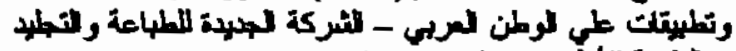

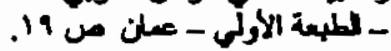


واستمر اريته بجانب أهمية الدور الأي تضطلع

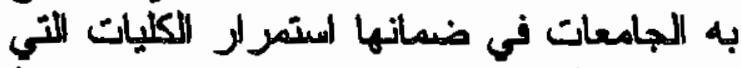

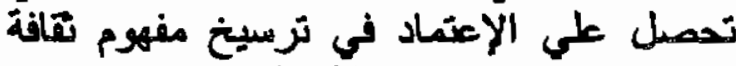

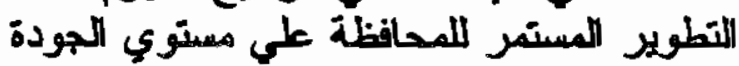
طبقا للمعايير المعتمدة.

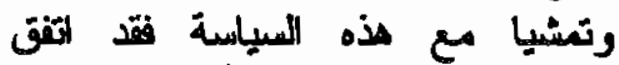

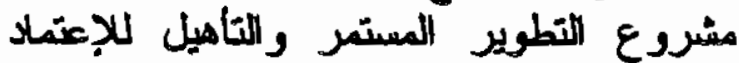
كطرف أول مع جادعة المنمسورة وكلية الهندية

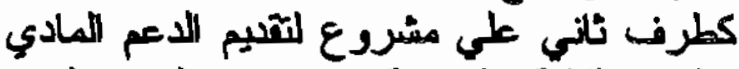

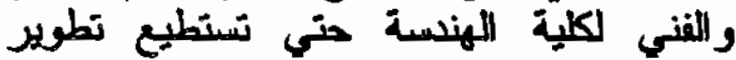

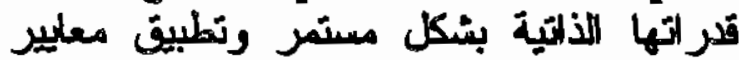

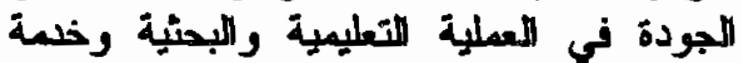

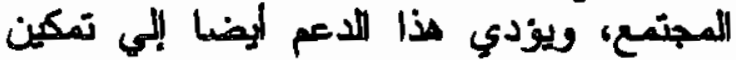
الكلية من نطويز البنية التحتية لها، وتطبيت معايير الجودة في تلنيذ المعلية التعليدية والبحئية

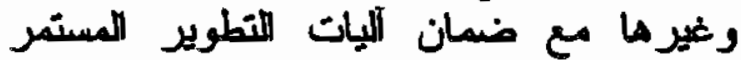

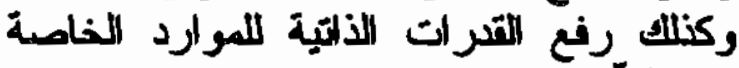

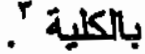

وتد تم إعتماد إلثثاه نظام معلومات

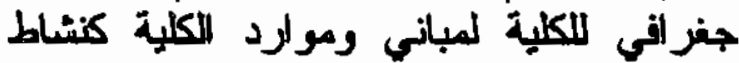

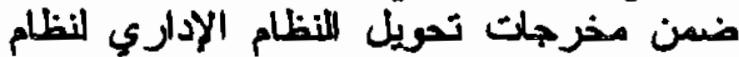

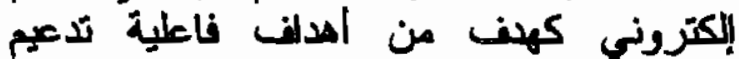
وتحسين التصرة المزوسية .

\section{I - 2014tise} تعتبر كلية الهندسة بالمنصورة من اولى فيلى

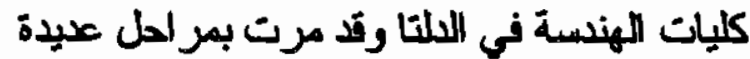
حتى وصلت إلى حالتها الآن فتد النشئ المعهد

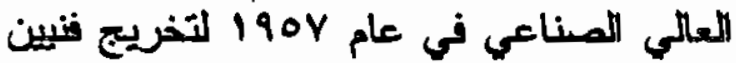
تطبيقيين، وفى عام 1971 التقسمت الدراسة

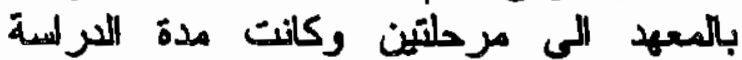

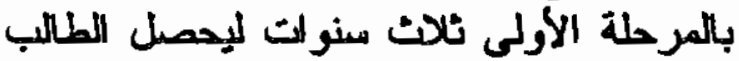

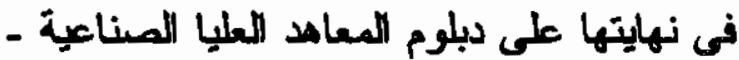

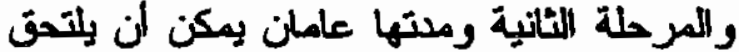

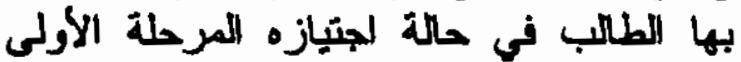

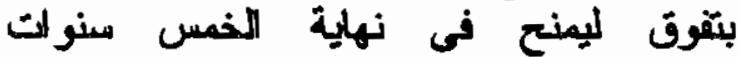

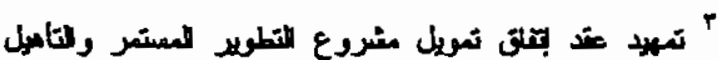

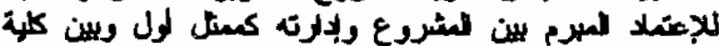

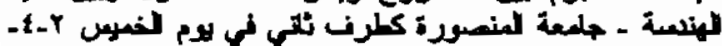

نظم المعلومات الجنغرافية في إنشاه

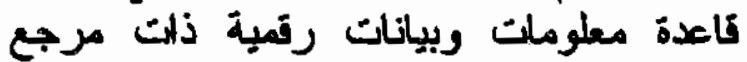
جنزافي عن الموارد المانية المتوفرة: تليبي

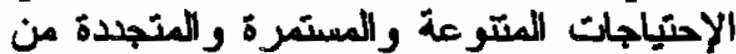

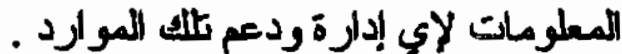
I Y-E

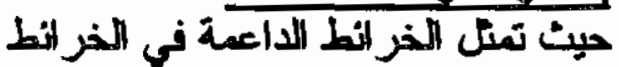

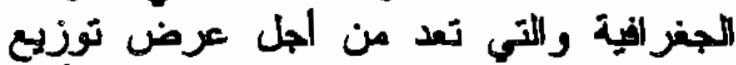
جغرافي لظاهرة (موضوع) واحدة علي الألها.

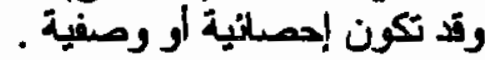

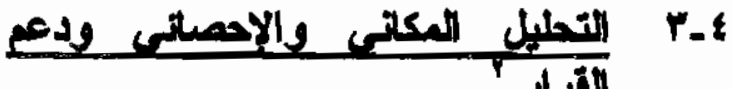

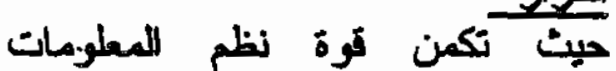

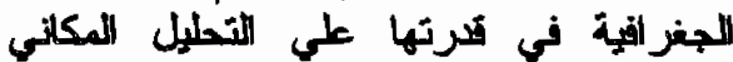

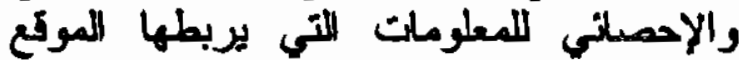
للجغرافي، إذ تصميز بكونها أداة ألموية ومهمة اللتحليل والتبنو بالتغير ات المستبلية، عن طريث

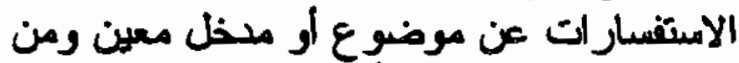

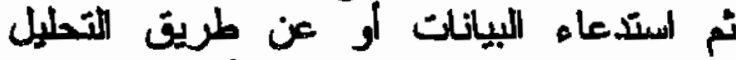

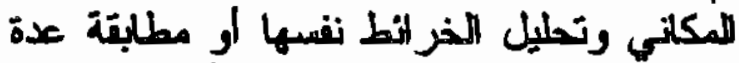

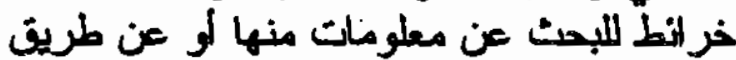

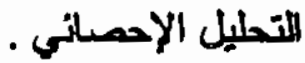

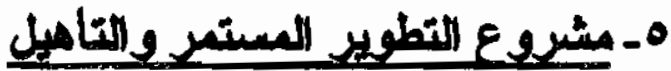

\section{(CIOAP)}

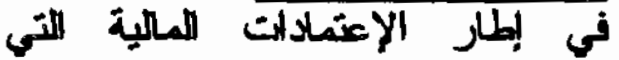

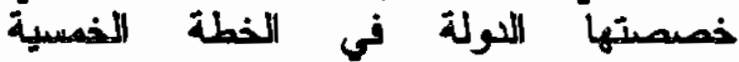

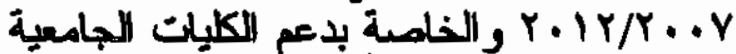

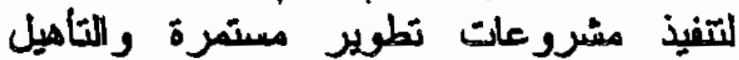

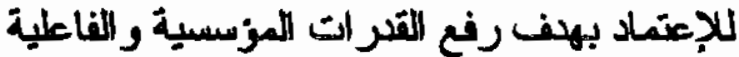

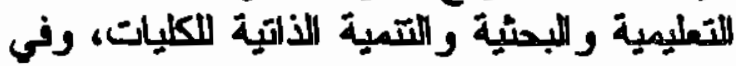

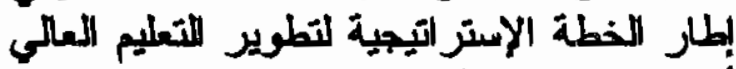
أعن كثير من الكليات الجامعية لستر التبجياتها

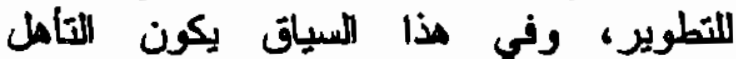
والحمبل علي الإعتماد من المينة المينة القومية

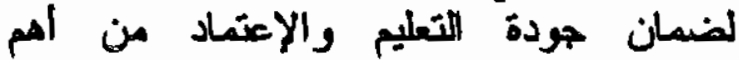

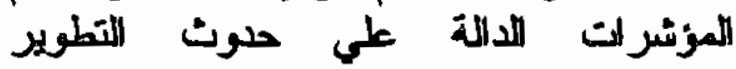

Minville, Erwan\& Souiah, sid-ahmed (2003), "l'analyse statistique et Spatiale: ststistique, cartographie,teledetection, SIG" edition du Tems,nantes.

' يجد المسد، نهزي - مرجع سليَ" 


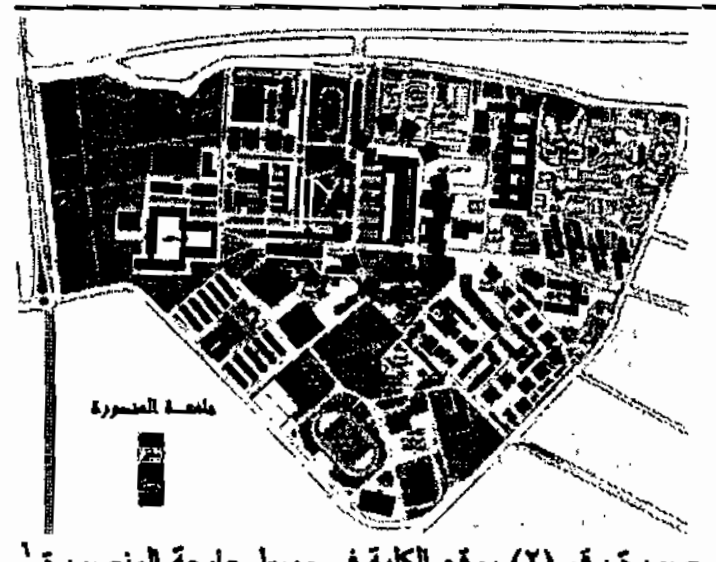

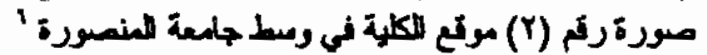

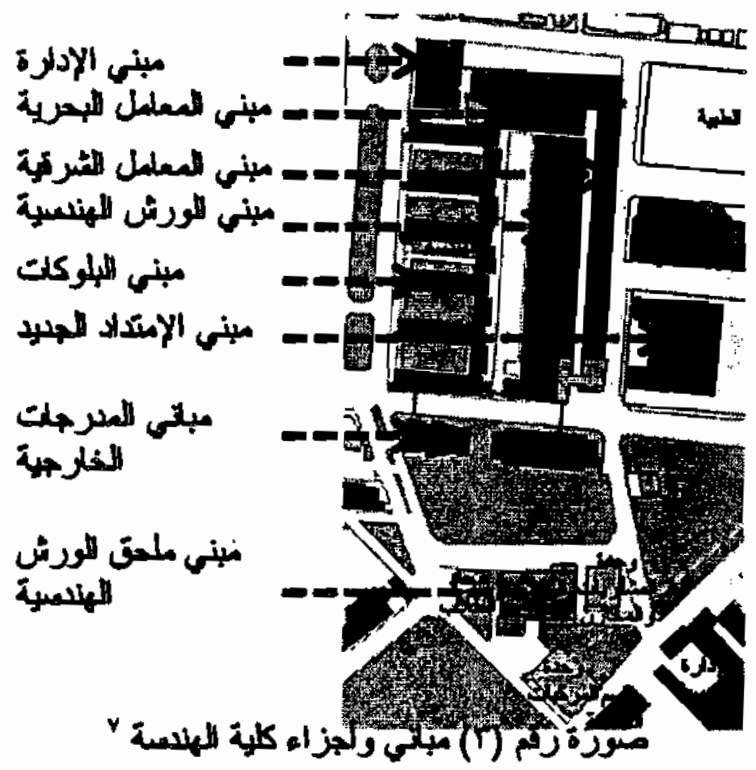

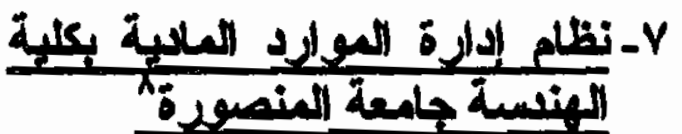

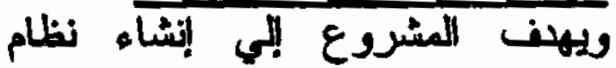

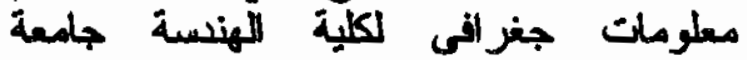

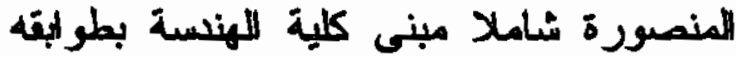

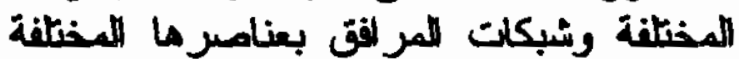

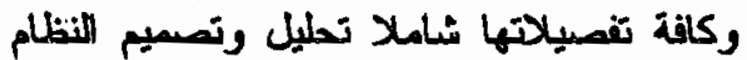

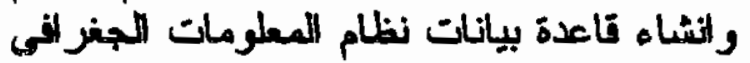

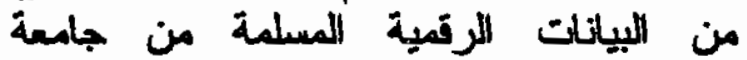

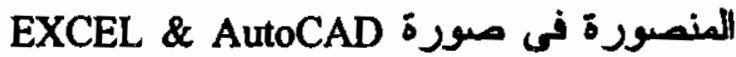
files و انشاه تطبيقات نظام المعلومات الجغر أفىي

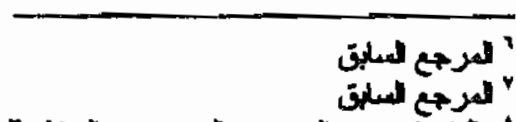

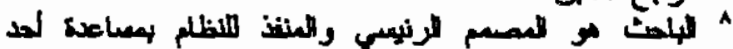

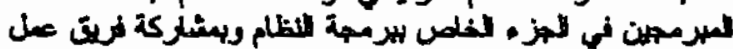

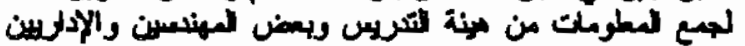
.25ly

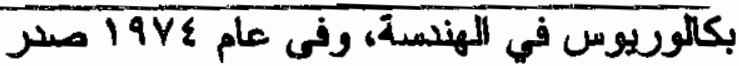

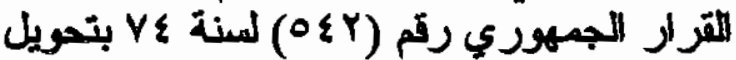

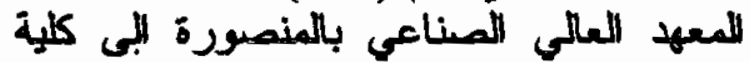

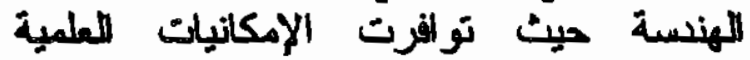

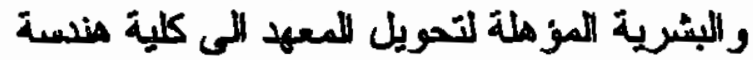

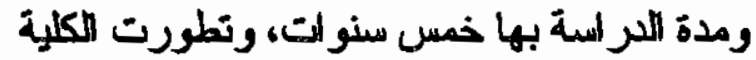

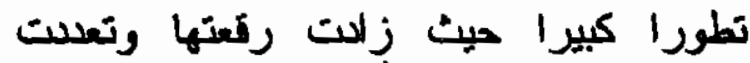

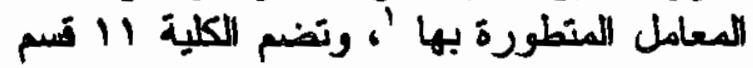

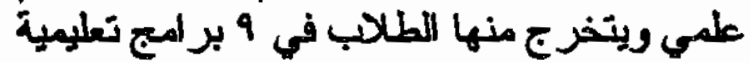

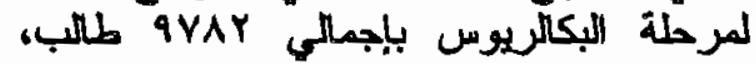

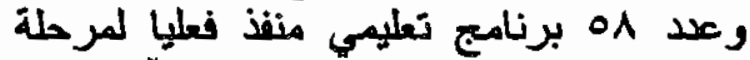

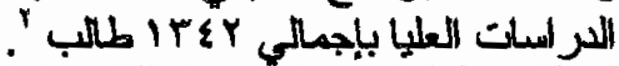

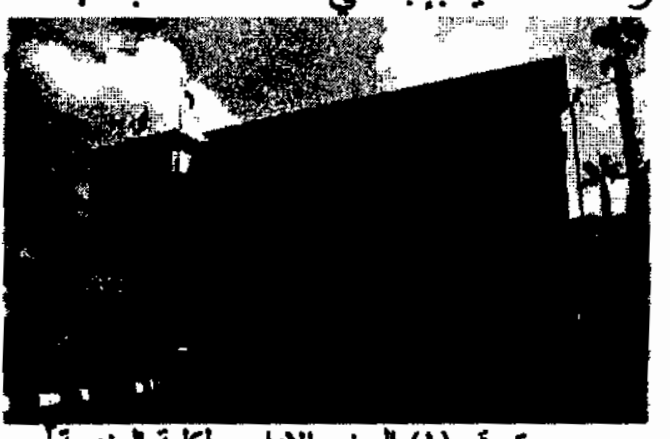

صورة رتم (1) اللعبني الإداري لكلية المهنسة'

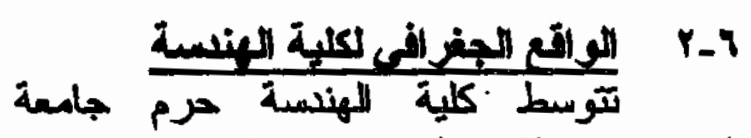

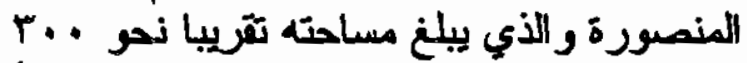

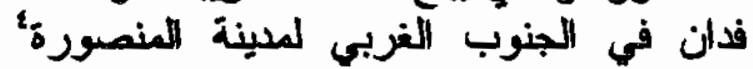

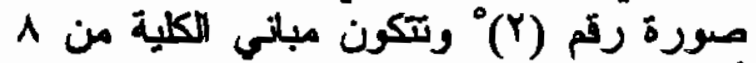

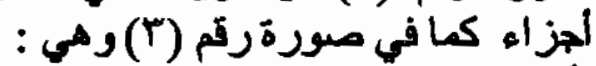

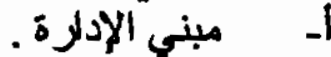

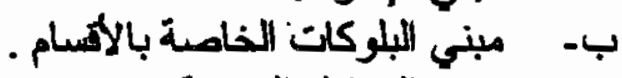

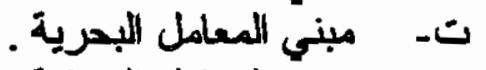

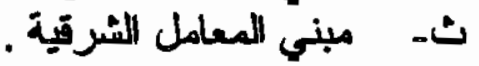

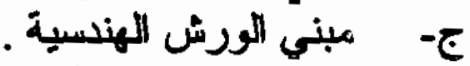

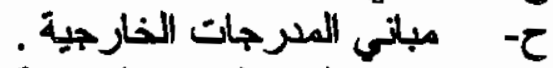

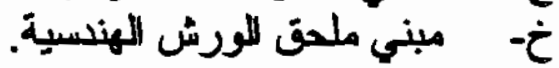

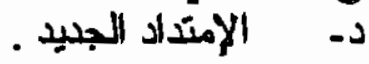

'http://www.mans.edu.eg/faceng/arabic/origination. htm

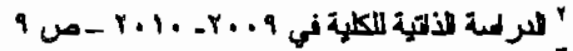

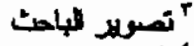

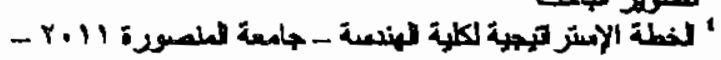

$$
\begin{aligned}
& \text { Yve- Y.10 }
\end{aligned}
$$

'http://www.mans.edu.eg/maps/emptymaps/map.ht m 
بالكلية، ومن ثم تصميم قَاعدة بياتات نظماتم المعلو مات الجغز افي و تحديد حقول البيانات من هيث الاسم و النوع و الحجم و العلاتفات بينها،

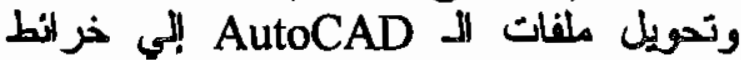
وإضيافة الاكواد الخاصة بتلك الموارد المادية المانية

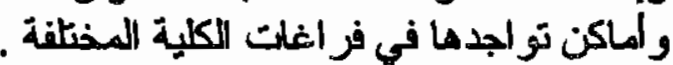

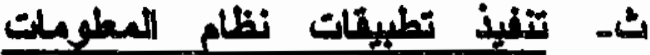

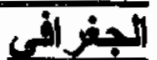

وتم تتفيذ التطبين شاملا شاشات الإدخال

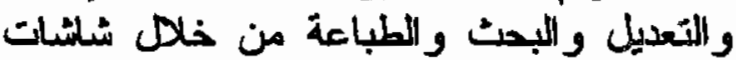

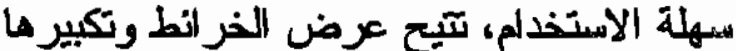

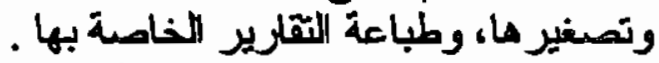

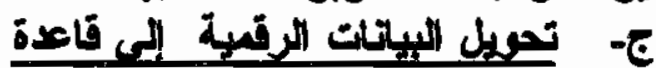
نئام المعلويل

تحميل وتشغيل نظام المعلومات التحريب

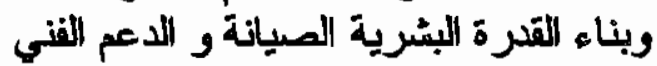

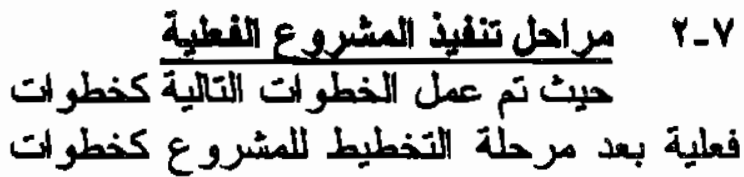

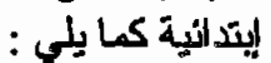

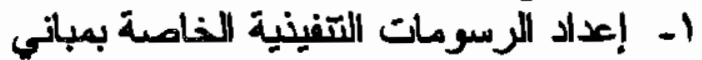

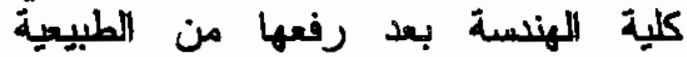
ومراجعتها ومر اجعة كافة اللفر اغات بها.

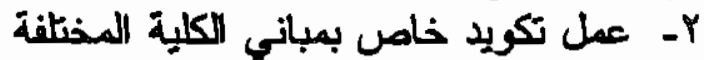

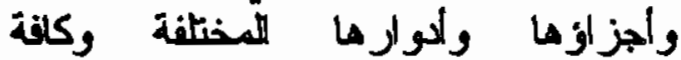

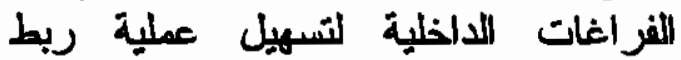

$$
\text { البياتات و المعلومات . المات }
$$

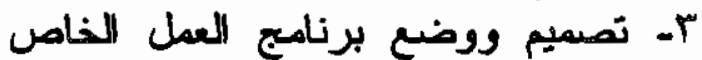

$$
\text { بعمليات توثئي الموارد المانية . }
$$

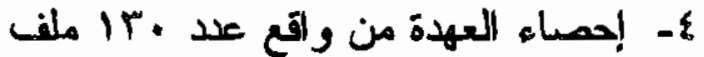

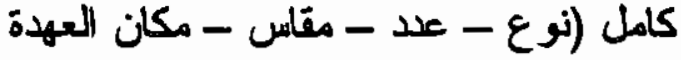

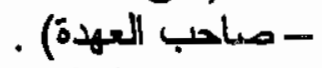

هـ الحصر الفعلي من الواقع للمواد الماد المادية

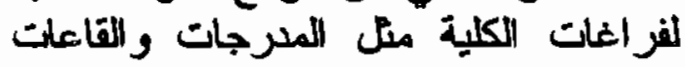
والمعامل والمكاتب ( كراسي - ترابيزات المات

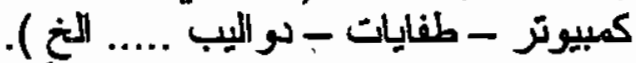
آ- تحديد الآكويد الذي سيتم علي علي الساسيه

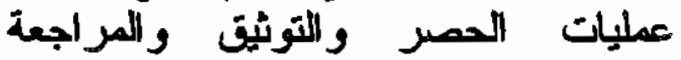
للموارد المانية للكلية على النحو التالىى :

\section{أكواد وأعداد المواري المسادية}

والأى تصلح مستمبلا للتعامل مع اي كلية أخرى داخل حرم الجامعة.

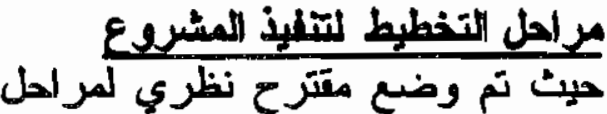

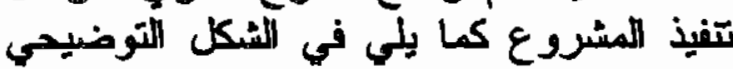
التاله ركم (1) : (1) :

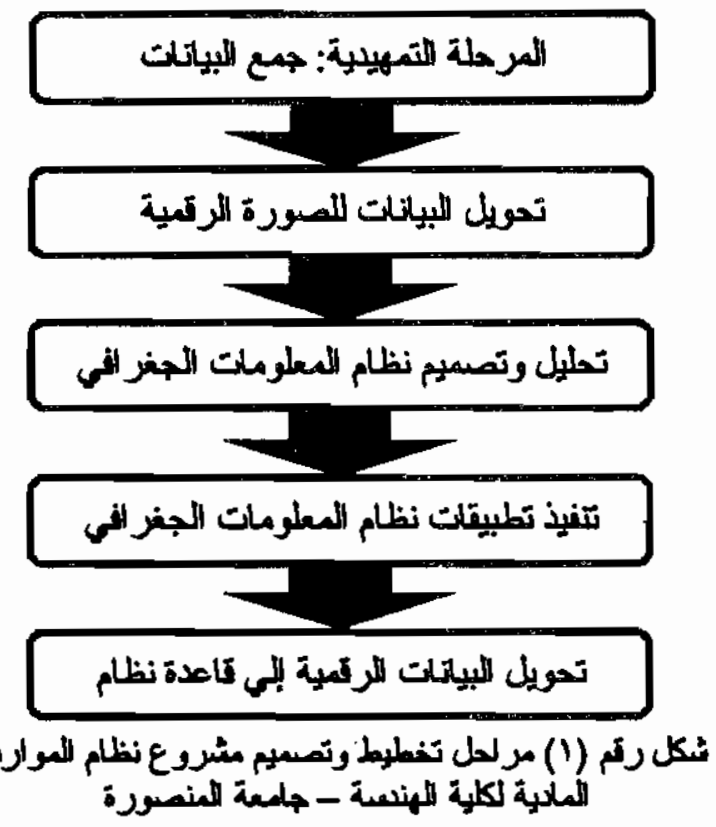

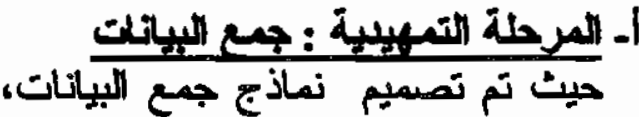
وتم جمع بيانات عن الأصول والموارد المادية بالكلية من حيث النوع و العدد والحالة والماكن والين

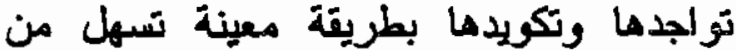

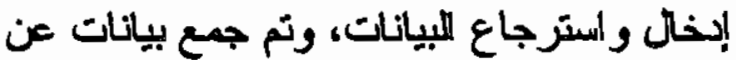
التصميمات الهنسية المثاحة عن مبني الكلية من مباني طوابق و غرف كما تم تكويدها.

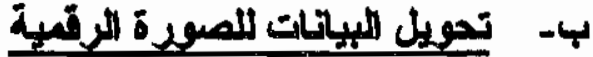
تم تحويل البيانات اللي صورديل Access

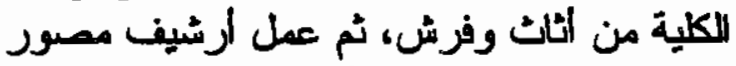

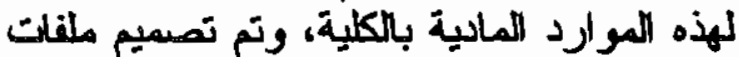
تن مبني الكلية في صور هـ AutoCAD.

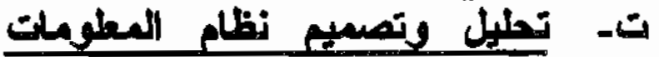

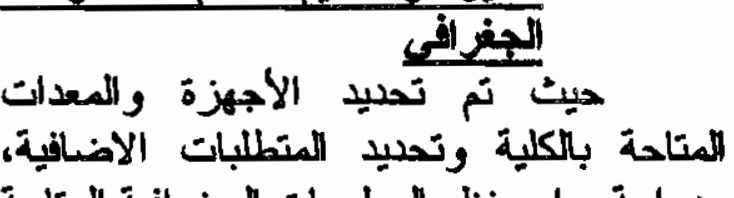
ور اسةة برامب نظم المعلومات الجغز افية المتاحة 


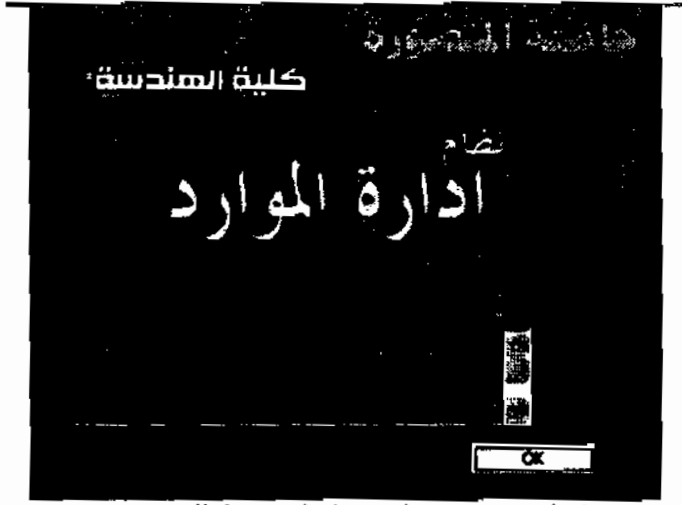

شُكل رقم (Y) الوأجهة اللرنيسية اللبرنلمج

ويضم النظام عدة قواتم رئيسيه بمكن الدخول الإِيها بعد عمليه أزيال البرنامج وتحميله

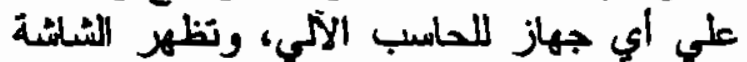

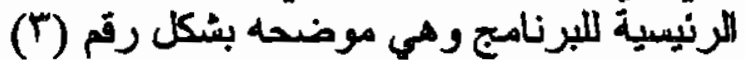

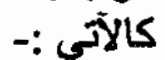

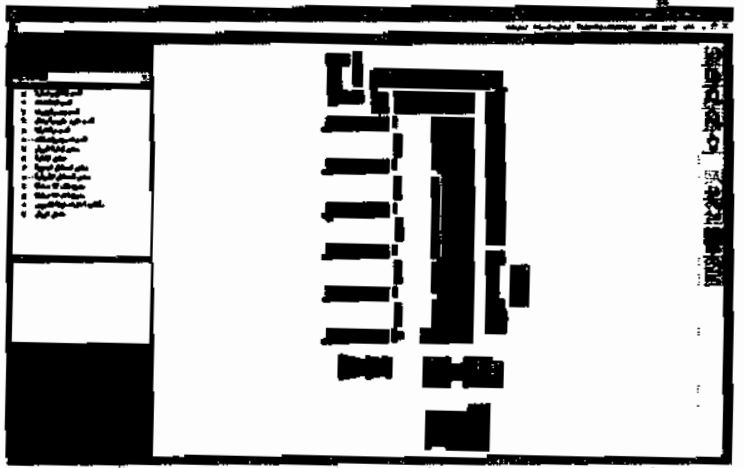

تُكل رقم (r) تعليا المواقع العلمة والرئنسية بلكلية

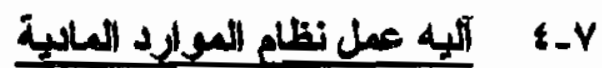

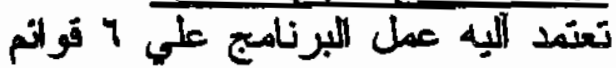
رئبسية هي ملف وتحرير وتثلرير وإدارة

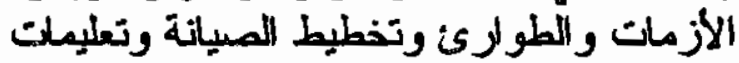

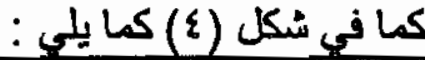

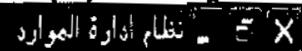

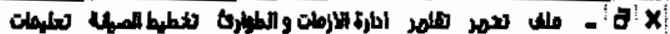
ثنكل رتم (ع) القر انم الرنبسة اللبرنلمج

كما يمكن تصنيد الأماكن الخاصة

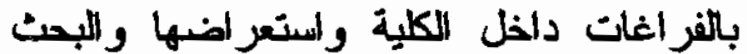

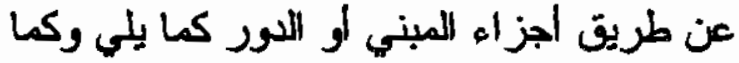

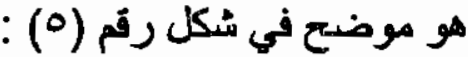

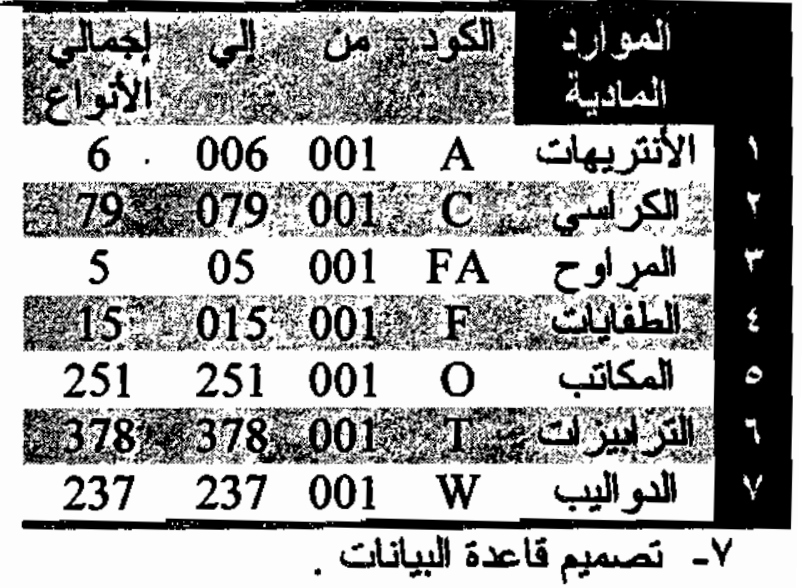

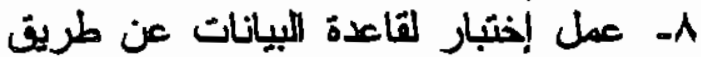

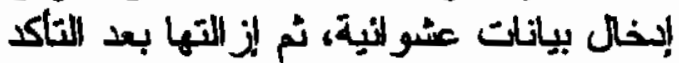

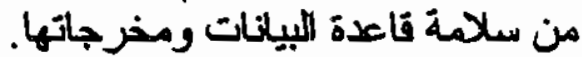

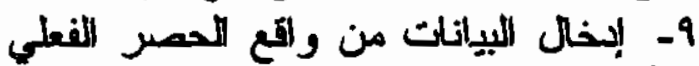
لأtاث الكانية. • ا-إدخال صور الإدماذج الخاصة بالموارد المانية للكلية الحنة

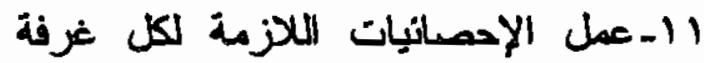

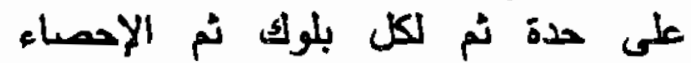
الإجمالي.

\section{r-V

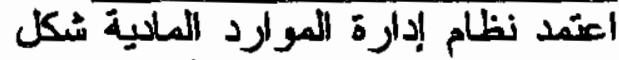

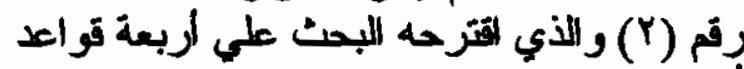

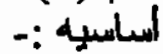

ا.تسهيل : عمليات إبخال وإبسترجاع

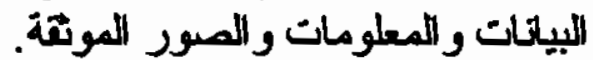
Y. ضرورة التعامل مع المعطيات الأساسيه والماتيه

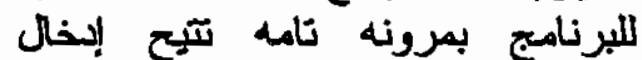

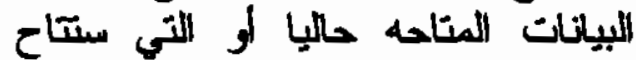

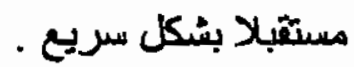
r. إمكانيه تطوير الإرنامج بشكل مسترب

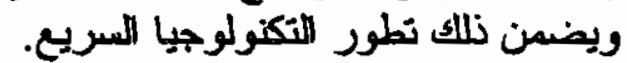

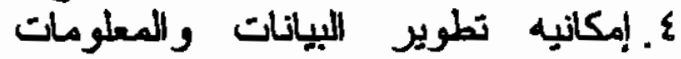

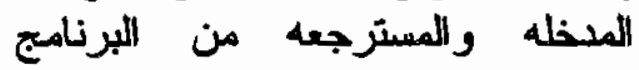

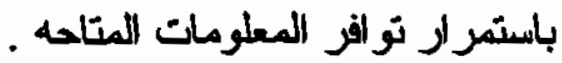


A. 19 Mohamed M. Shawky Abou-Liela

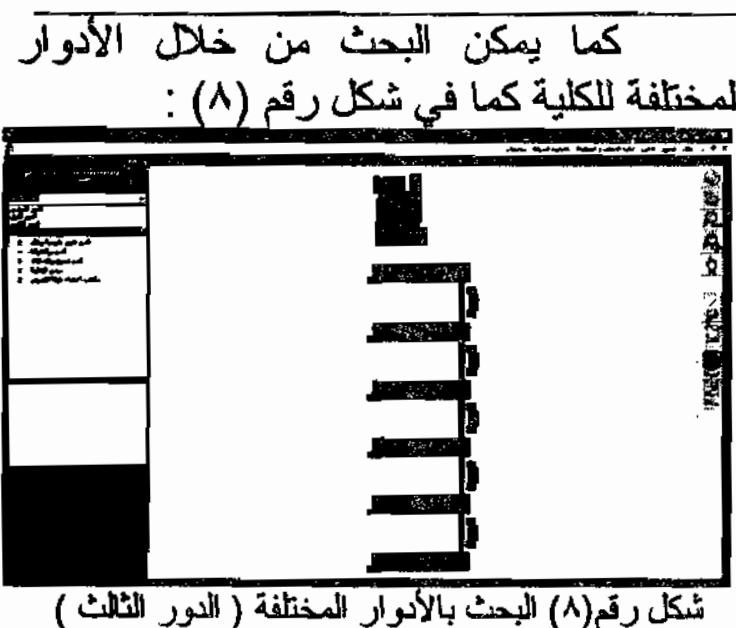

كذلك يمكن إضافة أو حنف أو تعديل إية بيانات كما في :

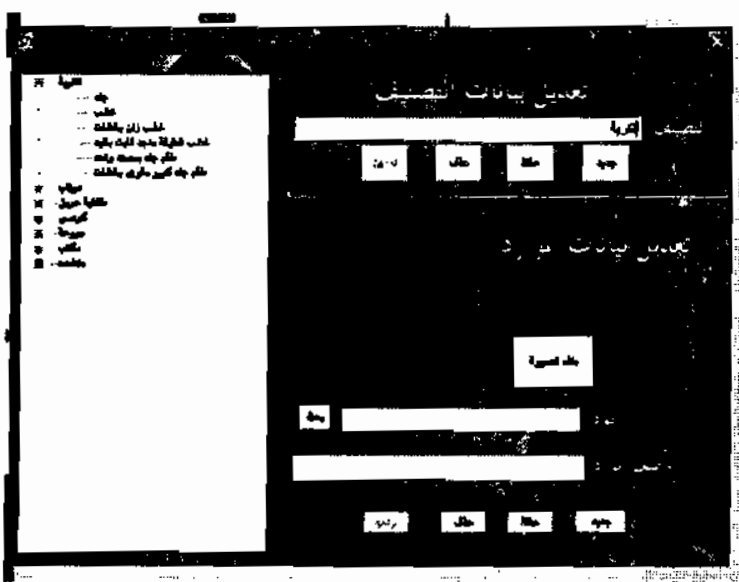

ثكل رقم (9) نعيل أو إضلفة لو حفت بيانات الاصنف

ويظهز النيكل التالمي رقم (•) صورة ومكونات فر اغ غرفة عميد الكلية كنموذج لما تم

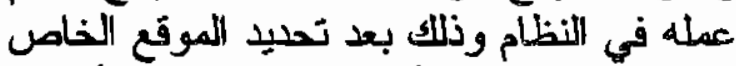

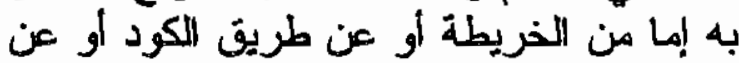

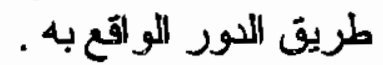

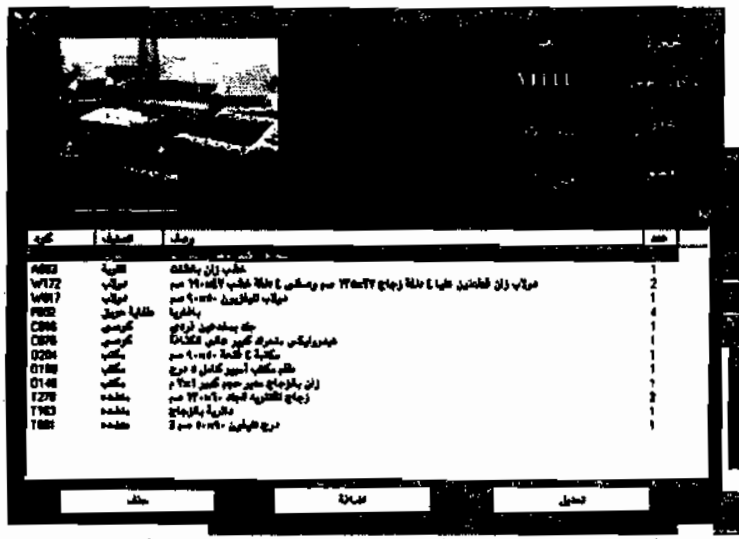

شكل رقم (· (1) غرفة عميد الكلية ومواردها المادية

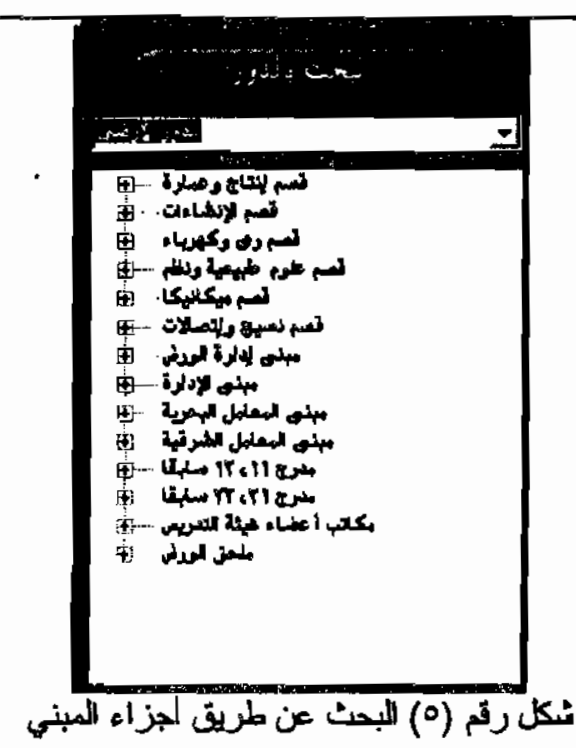

وتوجد عدة اختيار ات تفاعلية للبحث او

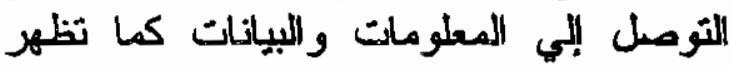

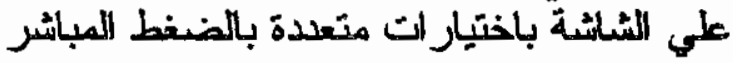

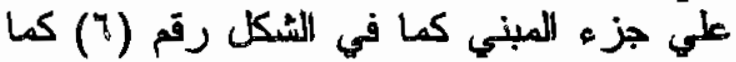

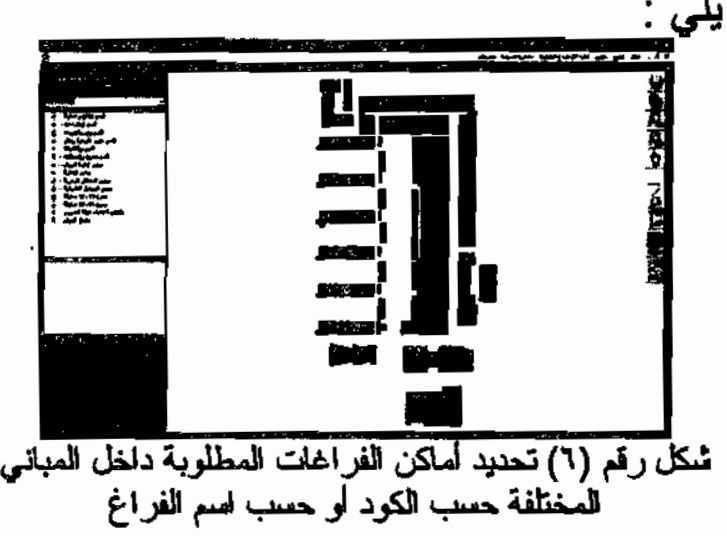

كما بمكن البحث عن قعم مصينة بعينه

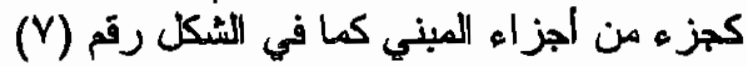

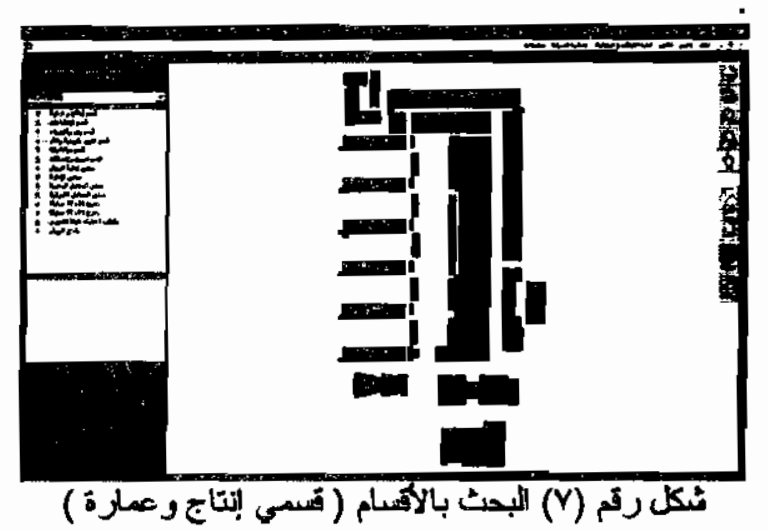

تُكل رقم (V) البحث بالأكسام ( قُمي إنتاج وعمارة ) 


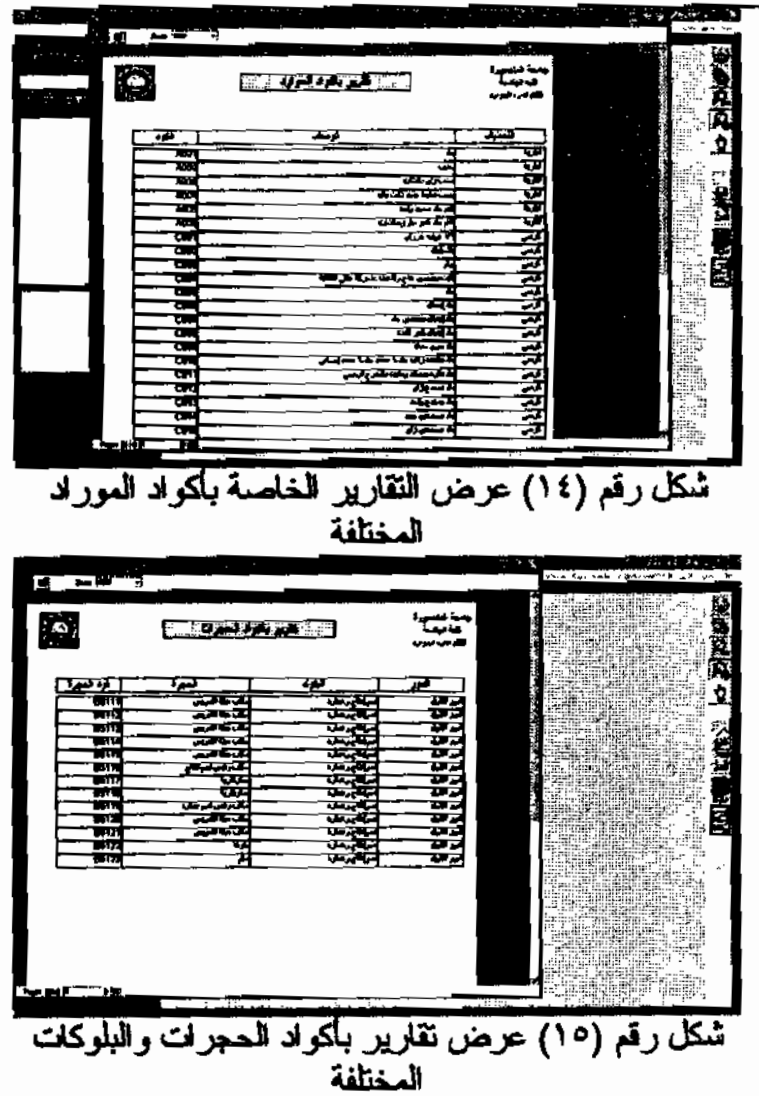

كما ينعرض النظام لسيناريو إدارة

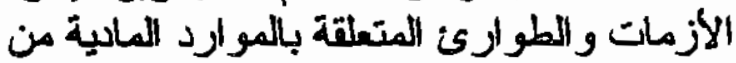

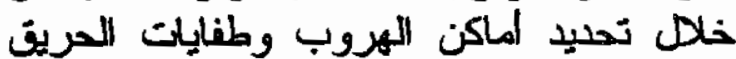

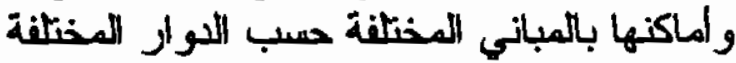
وكنلاك يمكن إنخال تاريخ ملاحيتها وكينية

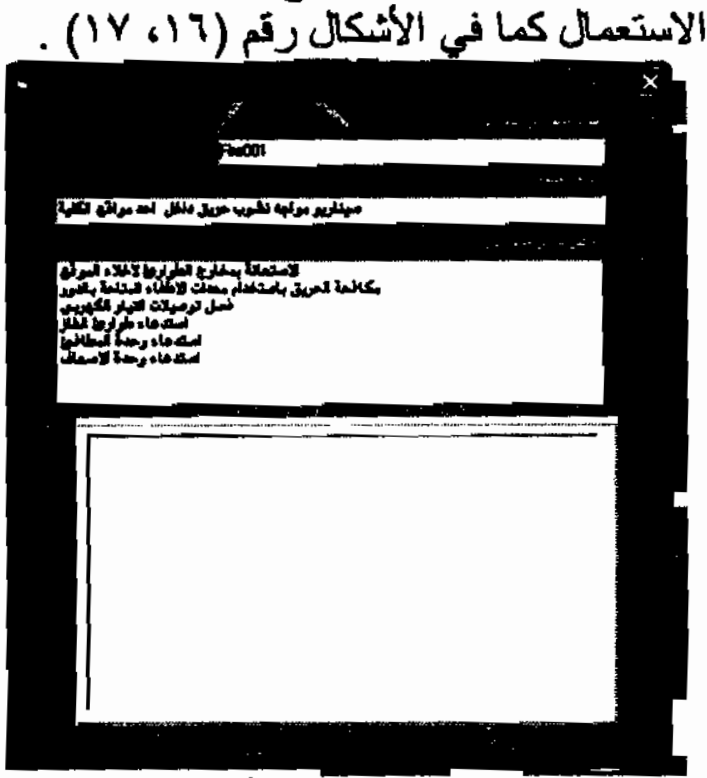

شكل رنم (14) سيناريو إدارة الأزمت والطوارئ
كنلك بيان هصر وشكل ونوعية كافة

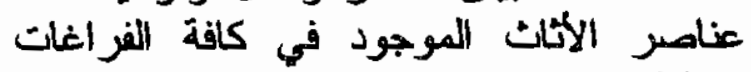

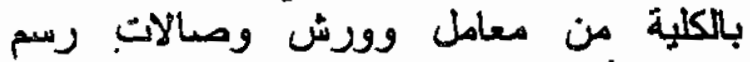
وغرف اعضاء هينة التريس و العاملين و الفنيين

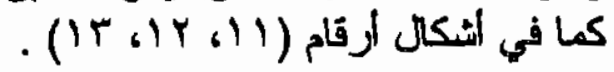
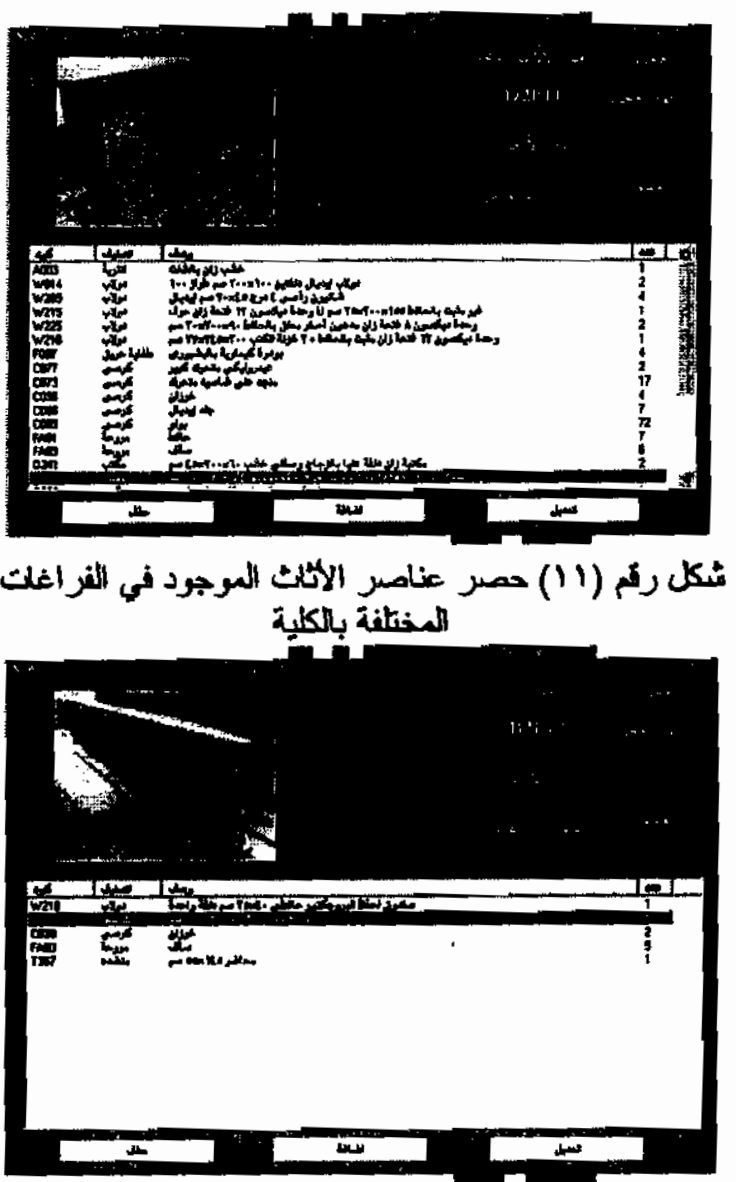

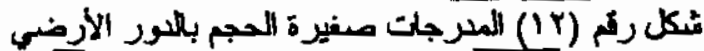

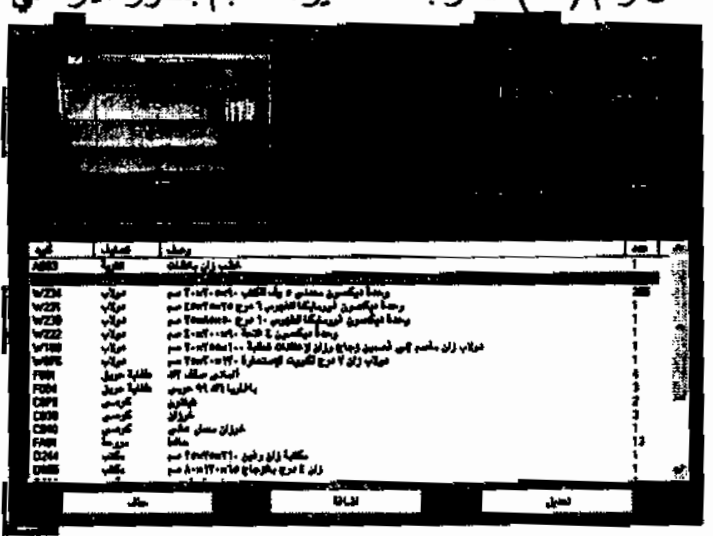

تيكل رقتم (TI) المكتبة ومواردها المعادية

كذلك بمكن الحصول علي الأقاريز و البيانات المتعلقة بهذا القز اغات وما بها كما في في لئي

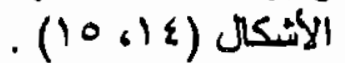




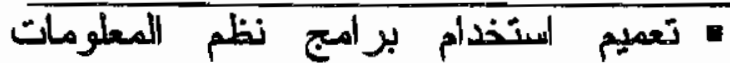
الجغرافية في جمبيع الجهات الحكومية لمبية

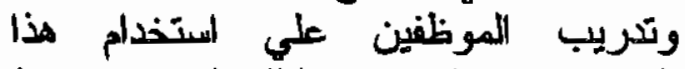

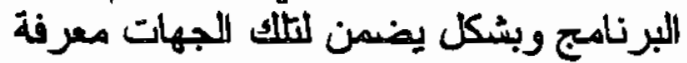

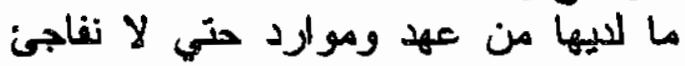

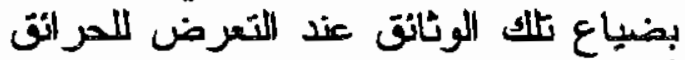
او الكو ارث الطبيعية .

ه تحديث جميع البيانات ومعلومات المنعلقة المبلة

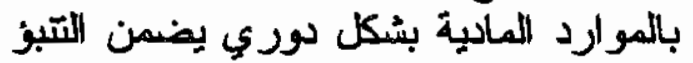

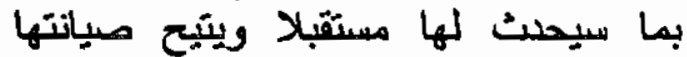

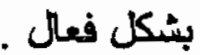

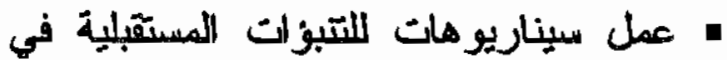
حالات الاعملال و الكوارث .

\section{المراجج:}

- Geography Matters ${ }^{\text {TM }}$ An ESRI (8) White Paper (September 2002)URL: http://www.gis.com/whatis gis/geographymatters.pdr

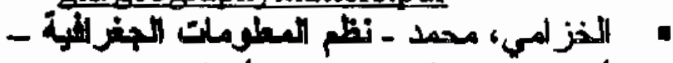

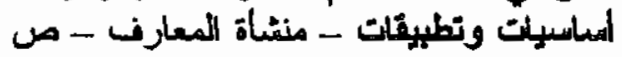
. (1991) - 11

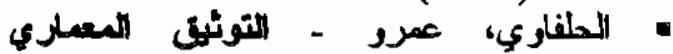

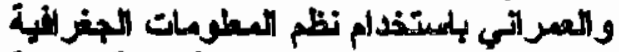

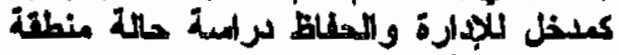

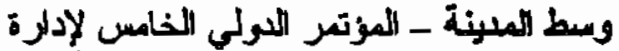

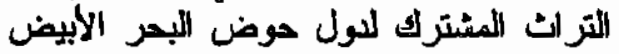

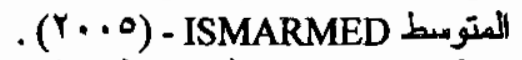

• صلامح، حسن عبد القار - المور اد ولتميتها:

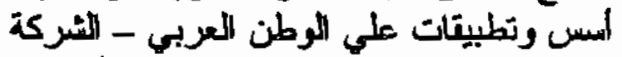

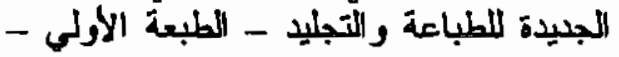

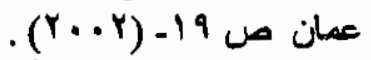
• تمهيد عتد إتفاق تمويل منروع المطوير

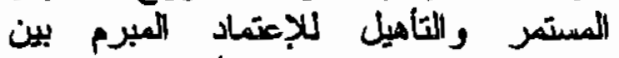

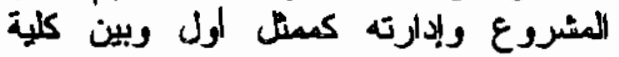

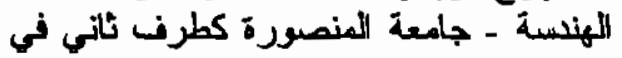

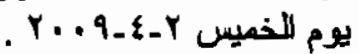

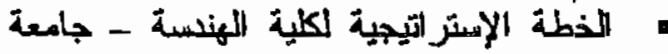
المنصسررة

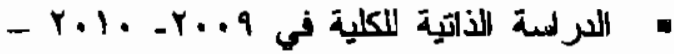
ص 9.

- http://www.mans.edu.eg/maps/emptymaps/ map.htm

- http://www.mans.edu.eg/faceng/arabic/originati on.htm

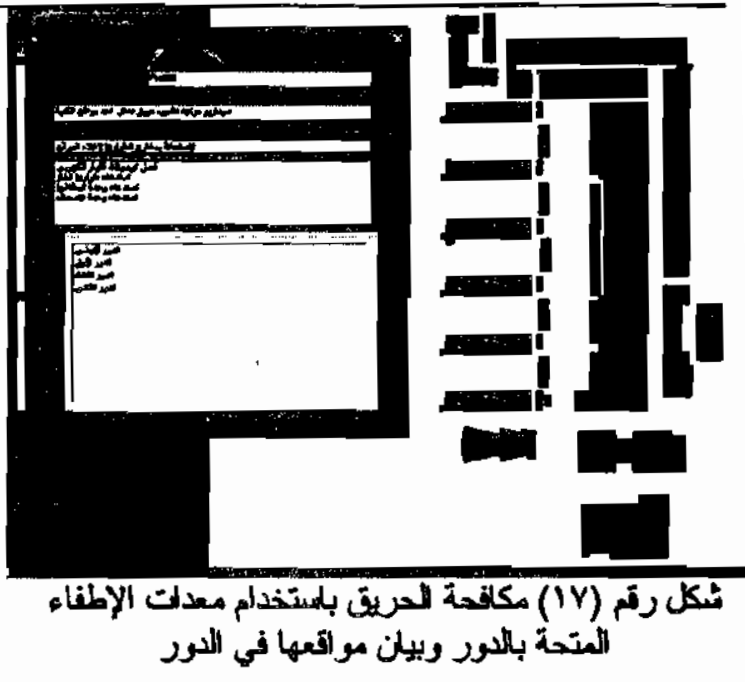

A- النتائه

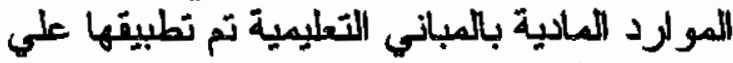

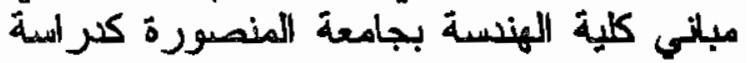
حالة يمكن تعميمها وتطبيقها علي باقي المباني المباني

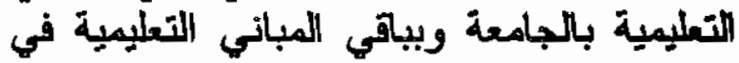

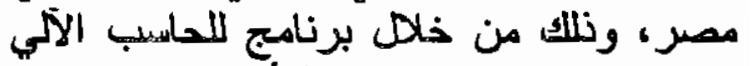

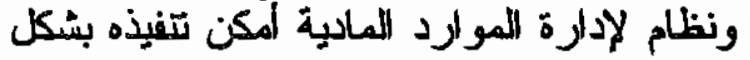
تقني مكن من تيسيير عمليات إلخال للبيانات

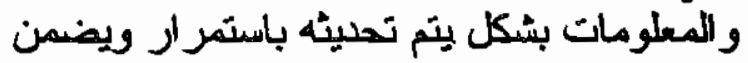

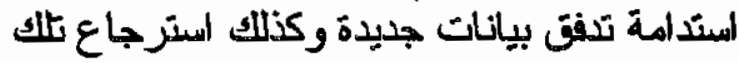

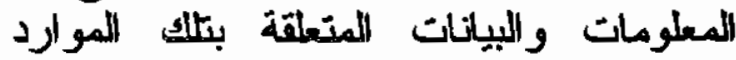

بو اسطة لستخدام نظم المعلومات الجغرات افية.

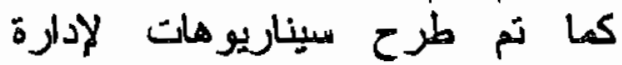

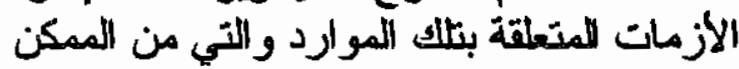

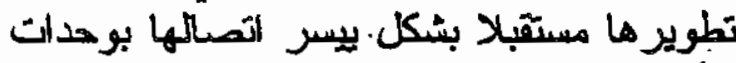

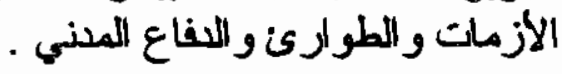

\section{9 - التوصيات}

• من الضروري التعامل مع المباني التعليمية ومواردها المادية بشكل يضمن ولئن المحافظة

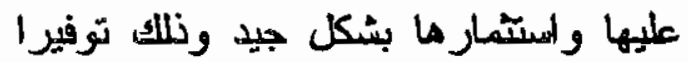

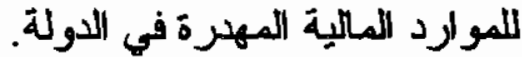

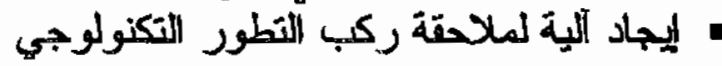
الأذي يتيح بناء سجلات إلكتية الكترونية للموارد

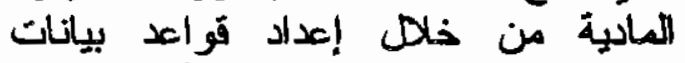
منكاملة مرنة تمكن من إضافة أو الدهيول علي البيانات في الي وقتث وبشفافية تامة. 
- Minville, Erwan\& Souiah, sid-ahmed (2003), "l'analyse statistique et Spatiale: ststistique, cartographie,teledetection,SIG" edition du Tems, nantes. 